\title{
Original article: \\ Single blinded in-vitro study comparing microleakage between CAD/CAM crowns milled out of feldspathic ceramic and resin nano ceramic, cemented with three resin cements Asa Yazdani Fard ${ }^{1}$, Zuryati Ab-Ghani', Zaihan Ariffin ${ }^{3}$, Dasmawati Mohamad ${ }^{4}$
}

\begin{abstract}
:
Background: Studies on microleakage of Computer-Aided Design/Computer-Aided Manufacturing (CAD/CAM) crowns are abundant. However many of them are inconclusive, especially those using self adhesive cements. Aims: To compare the microleakage between $\mathrm{CAD} / \mathrm{CAM}$ crowns milled out of feldspathic ceramic and resin nano ceramics, cemented with three resin cements. Materials and Methods: Crown preparation was made on 54 extracted human premolars. Impressions were captured optically using CEREC 3D machine intraoral camera, and crowns were milled from feldspathic ceramic (CEREC ${ }^{\circledR}$ Blocs PC, VITA) and resin nano ceramic (Lava ${ }^{\mathrm{TM}}$ Ultimate $\mathrm{CAD} / \mathrm{CAM}$ Restorative, 3M ESPE) blocks. The crowns were then cemented with three cements $(\mathrm{n}=9)$; RelyX ${ }^{\mathrm{TM}}$ U200 Self-Adhesive Resin Cement (3M ESPE); NX3 Nexus ${ }^{\circledR}$ cement with two-step etch-and-rinse adhesive (Kerr Corporation) or three/multistep etch-and-rinse resin cement, Variolink ${ }^{\circledR}$ II/Syntac Classic (Ivoclar Vivadent). The specimens were kept in water for 24 hours, thermocycled, and then soaked in methylene blue dye for 24 hours, before being sectioned mesiodistally. Microleakage was assessed using a fivepoint scale using stereomicroscope. Statistical analysis of the data was carried out using ONEWay ANOVA. Results: CEREC ${ }^{\circledR}$ Blocs PC crowns showed significantly less microleakage $(p<$ 0.001) compared to Lava ${ }^{\mathrm{TM}}$ Ultimate. Rely $\mathrm{X}^{\mathrm{TM}} \mathrm{U} 200$ showed significantly lower microleakage $(p<0.001)$ compared to other cements. Combination of Lava ${ }^{\mathrm{TM}}$ Ultimate crown cemented with RelyX ${ }^{\mathrm{TM}} \mathrm{U} 200$ showed the least microleakage $(p<0.001)$. Conclusions: The microleakage scores were affected by the types of crown and cements.
\end{abstract}

Keywords: CEREC 3D; self-adhesive resin cement; 'CAD/CAM' resin nano ceramic crowns, microleakage

Bangladesh Journal of Medical Science Vol. 18 No. 04 October'19. Page : 764-772 DOI: https://doi.org/10.3329/bjms.v18i4.42883

\section{Introduction}

The demand for all ceramic restoration is in the increase due to the improvement in the properties of ceramics. ${ }^{1}$ Computer-Aided Design/ ComputerAided Manufacturing (CAD/CAM) technology allows a single visit all-ceramic restoration in dental practice, eliminating the need for laboratory work, several impressions and also temporary restorations. 2 CEREC (Chair-side Economical Restoration of Esthetic Ceramics or Ceramic Reconstruction) allows the production of an indirect ceramic dental restoration using $\mathrm{CAD} / \mathrm{CAM}$. CAD/CAM crowns can be generated from ceramic blocks or composite blocks. A new CAD/CAM block, resin nano ceramic

1. AsaYazdani Fard, Dorin Special Dental Clinic, No 32, Yousefabad Avenue, 6 District, Tehran, Iran. Email.; dr.asa.fard@gmail.com

2. Zuryati Ab-Ghani, Prosthodontic Unit, School of Dental Sciences, Health Campus, Universiti Sains Malaysia, 16150 Kubang Kerian, Kelantan, Malaysia. Email; zuryati@usm.my

3. Zaihan Ariffin, Prosthodontic Unit, School of Dental Sciences, Health Campus, Universiti Sains Malaysia, 16150 Kubang Kerian, Kelantan, Malaysia. Email; zaihan@usm.my

4. Dasmawati Mohamad, School of Dental Sciences, Health Campus, Universiti Sains Malaysia, 16150 Kubang Kerian, Kelantan, Malaysia. Email: dasmawati@usm.my

Correspondence to: Assoc. Prof. Dr. Zuryati Ab-Ghani, Prosthodontic Unit, School of Dental Sciences, Health Campus, Universiti Sains Malaysia, 16150 Kubang Kerian, Kelantan, Malaysia. E-mails: zuryati@usm.my, zuryatiabghani@gmail.com 
(Lava $^{\mathrm{TM}}$ Ultimate, 3M ESPE, St. Paul, MN) is a mix of composite and ceramic in which it contains zirconia nanoparticles. It has been suggested that resin nano ceramic is easier to handle which is similar to composite. Furthermore its gloss and finish retention mimics porcelain. It is also less abrasive to their opposing teeth, in comparison to ceramic. A search on articles published from1966 to 2013 concluded that there is still not enough documented data regarding the performance of these new polymer materials (Lava Ultimate), hence the need for further research in this area. ${ }^{3}$

Good cements should provide sufficient sealing ability to prevent microleakage between tooth structure and fitting surface of restoration. ${ }^{4}$ Marginal leakage will lead to marginal staining, secondary caries, and subsequent pulp infection. ${ }^{[5,6]}$ The earlier generations of the adhesives involves three main steps of etching, priming and bonding application, and they are technique sensitive. ${ }^{7,8}$ Newer generations of self-adhesives cements which are capable of selfetching and bonding to dentine are easier to handle and less technique sensitive. ${ }^{9}{ }^{10}$ However, Monticelli et $a l^{11}$ in 2008 reported that the hybrid layer was not fully created due the inability to completely demineralise the smear layer by the self- adhesive cements. This study however, was contradicted by other studies. ${ }^{12,13,14}$ Due to the inconclusive reports, more studies need to be conducted to assess the microleakage of machined crowns made with the new resin nano ceramic blocks. The new self-adhesive cement need to be studied as well.

Thus, in this study, the comparison of microleakage was made between the CAD/CAM feldspathic and resin nano ceramic crowns which were cemented with self-adhesive resin cement and also conventional resin cements.

\section{Materials and Methods:}

This was a single blinded, randomised experimental study, carried out in-vitro. Sample size was calculated by comparing two means using PS software (Dupont and Plummer, 1997). To detect the difference of 1.4 (microleakage score), standard deviation estimated at 0.9 microleakage score ${ }^{15}$ we needed to study eight subjects per group, to allow us to reject the null hypothesis with probability (power) 0.8 . The Type I error probability associated with this test of this null hypothesis was 0.05 . Considering the probability of $10-15 \%$ damage to the samples, $(n=9)$ a total of 54 samples were needed. Human premolar teeth which were intact, with similar size and shape were chosen. They were then sterilized, any debris was cleaned and remaining calculus was scaled. All teeth were stored in saline. ${ }^{16}$

All procedures and assessments were carried out by one investigator to standardize the procedure. Crown preparation was done on each tooth following recommendation for the CEREC-3D system which include $1 \mathrm{~mm}$ reduction for axial wall, $2 \mathrm{~mm}$ reduction occlusally, heavy chamfer with rounded internal angles and butt joint margins. High-speed handpiece was used to cut tooth structure together with diamond burs. This preparation was cooled with water spray.

The teeth were then sprayed with reflective powder (Opti spray). Optical impressions of the prepared teeth were then made with the intraoral camera of the CEREC 3D system (Sirona Dental Systems GmbH, Bensheim, Germany). The design of the crowns was carried out by the machine, and the digital data was transferred to the milling machine. During the crown design, the cement space was set at ten $\mu \mathrm{m}$, whilst the marginal space was set at zero $\mu \mathrm{m}$. Twenty seven crowns were milled using ceramic blocks, CEREC $^{\circledR}$ Blocs PC, shade S2, size 12, (VITA Zahnfabrik Germany) and twenty seven crowns were milled from resin nano ceramic blocks, Lava ${ }^{\mathrm{TM}}$ Ultimate $\mathrm{CAD} /$ CAM Restorative for CEREC Blocs, size 12, shadeA2 (3M ESPE Dental St. Paul MN). Burs were changed based on the CEREC machine recommendations. Milled crowns were seated on the teeth and adjusted accordingly. The milling bar was then removed using the polishing disks. All procedures followed the manufacturer recommendations.

The fitting surface of Lava ${ }^{\mathrm{TM}}$ Ultimate CAD/CAM Restorative crowns were sand blasted with $50 \mu \mathrm{m}$ aluminum oxide powder using a sandblasting machine microetcher (Microcab, Danville Engineering Inc, San Ramon, CA). The fitting surface was then silanated with silane coupling agent (Ultradent, South Jordan, UT). On the other hand, the fitting surface of CEREC ${ }^{\circledR}$ Blocs PC crowns were etched with 5\% hydrofluoric acid Porcelain etch, (Ultradent, South Jordan, UT), and followed by silanation.

Block randomization method was used to divide the prepared teeth into six groups $(n=9)$ according to the types of blocks and cements used. For teeth to be cemented with Variolink ${ }^{\circledR}$ II/Syntac Classic (IvoclarVivadent, Liechtenstein), dentine surface was etched for 15 seconds with 37\% phosphoric acid (Batch Number S04037, IvoclarVivadent, Liechtenstein) washed with water spray, and then dried with air. A layer of Syntac primer (Batch Number S00833, Ivoclar Vivadent, Liechtenstein) and then Syntac adhesive (Batch number S07235, 
Ivoclar Vivadent, Liechtenstein) were then applied respectively, followed by application of Heliobond (Batch Number S04976, Ivoclar Vivadent, Liechtenstein), and light-cured for 15 seconds with an LED light curing unit, Elipar Free Light 2 (3M ESPE, Germany).

For teeth to be cemented with NX3 Nexus ${ }^{\circledR}$ (Kerr Corporation, USA), etching was done on the dentine surface for 15 seconds with $37 \%$ phosphoric acid, then washed with water spray, before being gently sprayed dried with air. This was followed by the application of Optibond Solo Plus (Batch Number 4702096, Kerr Corporation, USA) with a micro brush before being light cured for 15 seconds.

No treatment was needed on the dentine surface of teeth to be cemented with RelyX ${ }^{\mathrm{TM}}$ U200 (3M ESPE Dental St Paul MN). The cement was mixed, and then loaded onto the crown for cementation. Light curing was done for 20 seconds on each surface of the cemented crowns.

All crowns in all groups were cemented to the teeth according to their respective cements using finger pressure for two minutes. All procedures follow manufacturer recommendation. The materials are described in Table 1.

Table 1: The ceramic blocks, cements and adhesive

systems used in the study

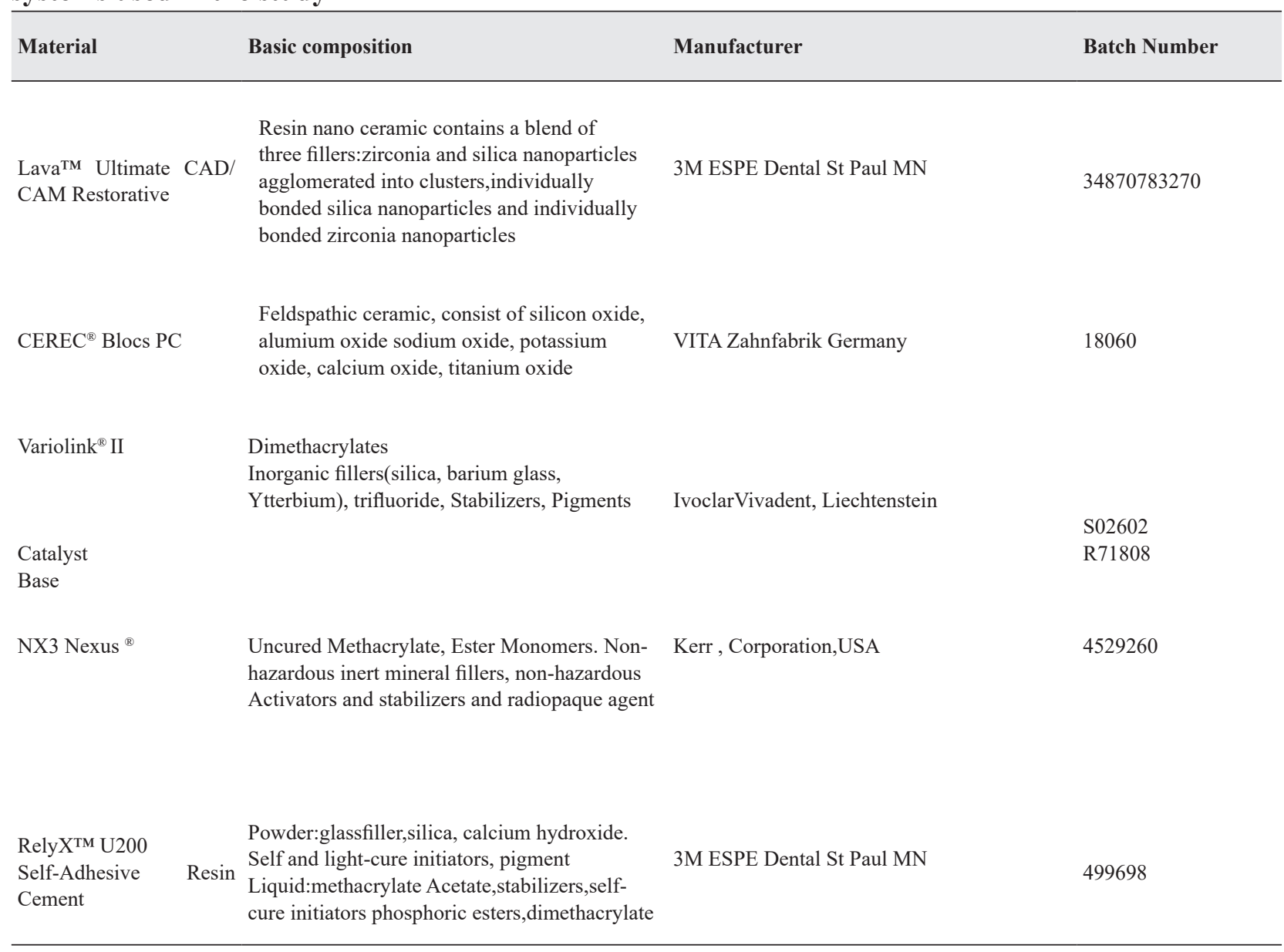

After cementation all samples were kept in water for 24 hours at $37^{\circ} \mathrm{C}$ to allow for complete setting of the cement. All samples were then thermocycled between $5^{\circ}-55^{\circ} \mathrm{C}$ water baths, for 3000 cycles with 30 seconds dwell times in between. ${ }^{17,18}$

Sticky wax was applied at the root apex to prevent dye penetration within the pulp and dentinal tubules. Nail varnish was applied to cover all surfaces except $1 \mathrm{~mm}$ from the restoration margin. Five percent methylene blue dye was used to trace the microleakage between crown and tooth preparation. All teeth were immersed in the dye for 24 hours. Slow-speed Isomet saw (Buehler, Illinois, USA) was used to cut each tooth mesiodistally into two halves. Water was used to cool the specimens during cutting process. ${ }^{2}$

After that, the specimens were viewed under Leica stereomicroscope Q550 MW (Leica, Heerbrugg, Switzerland) at X17 magnification. Each section has two reading sites, so from all the 108 halves (54 teeth) a total of 216 sites were checked and scored 
following chart shown below. ${ }^{2}$

0 .................... DO DY PENETRATION

$1 \ldots . . . \ldots \ldots \ldots . . . . . .2 Y E$

PENETRATION

ALONG THE GINGIVAL WALL.

$2 \ldots \ldots \ldots \ldots \ldots \ldots$.......... PENETRATION UP

TO1/2 AXIAL WALL.

3...................DYE PENETRATION MORE

THAN HALF TO FULL LENGTH Of AXIAL

WALL.

4.....................DYE

PENETRATION

EXTENDING TO THE OCCLUSAL WALL.

Six extra teeth, as representative of each study groups were prepared following the exact same procedure explained above. After cementation, teeth were stored in one hundred percent humidity for four weeks. Cross-sections of an approximate thickness of $1 \mathrm{~mm}$ were obtained from the teeth in mesio-distal direction by water-cooled slow-speed diamond saw (Exact Apparatebau, Germany). The specimens were desiccated and mounted on 26 $\mathrm{mm}$ aluminum stubs using special double-sided conductive tapes. Samples were then coated with gold, as an electrically conductive material, applied using a sputter-coater machine for six minutes. Teeth were then placed in SEM vacuum chamber in order to assess the interfacial gap between cements and dentine under and 8000X magnification.

All data were analyzed using SPSS version 20. Independent $t$ test and One way ANOVA test were used, with $p<0.05$ considered to be significant.

A second assessment of microleakage scores consisting of thirty percent of the data were made one week later to test for reliability of the investigator. Independent $t$ test was made comparing two means. The results showed no significant difference between the two means with $p<0.05$.

Ethical clearance: The study was obtained from the research and ethical committee of the institution.

\section{Results:}

Microleakage scores were obtained from 216 sites of the six experimental groups. All teeth remained intact and no teeth have been excluded from the study. Kolmogorov-Smirnov a test result showed $p<0.05$ for both cements and blocks, which shows that the data were not normally distributed. However as the sample size were more than 30 , we applied the Central Limit Theoram, and proceeded with the parametric tests.

Based on the Levene's test result, $p$ value was 0.009. Significant result suggests that the variance microleakage scores across group were not equal. A more stringent level of significance level (0.01) was applied; however, the assumption was still not met. Therefore, a two-way ANOVA could not be performed. The samples were split to conduct an analysis of simple effect using independent $t$ test for the blocks and one-way ANOVA for the cements.

Table 2 shows comparison of microleakage scores between CAD CAM blocks. Independent $t$ test shows a significant difference in the microleakage between the blocks with CEREC ${ }^{\circledR}$ Blocs PC showing higher microleakage scores than Lava ${ }^{\mathrm{TM}}$ Ultimate.

Table 2: Comparison of mean (SD) microleakage scores between CAD/CAM blocks

\begin{tabular}{|c|c|c|c|c|c|}
\hline \multirow[b]{2}{*}{ Variable } & \multicolumn{2}{|c|}{ Mean (SD) } & \multirow{2}{*}{$\begin{array}{c}\text { Mean } \\
\text { difference } \\
(95 \% \mathrm{CI})\end{array}$} & \multirow[b]{2}{*}{$\begin{array}{c}\text { T statistic } \\
\text { (df) }\end{array}$} & \multirow[b]{2}{*}{ p value* } \\
\hline & $\begin{array}{l}\text { CEREC }^{\circledR} \\
\text { Blocs PC }\end{array}$ & $\begin{array}{l}\text { Lava }^{\mathrm{TM}} \\
\text { Ultimate }\end{array}$ & & & \\
\hline $\begin{array}{l}\text { Microleakage } \\
\text { scores }\end{array}$ & $\begin{array}{c}2.67 \\
(1.168)\end{array}$ & $\begin{array}{c}1.58 \\
(1.291)\end{array}$ & $\begin{array}{l}1.083 \\
(0.753, \\
1.414)\end{array}$ & $\begin{array}{l}6.467 \\
(214)\end{array}$ & 0.000 \\
\hline
\end{tabular}

Independent $t$ test

Table 3 shows the descriptive statistic of microlekage scores of cements.

Table 3: Descriptive analysis of mean (SD) microleakage scores of cements

\begin{tabular}{|c|c|c|c|c|}
\hline & \multirow{2}{*}{$\mathbf{N}$} & \multirow{2}{*}{$\begin{array}{c}\text { Mean } \\
\text { (SD) }\end{array}$} & \multicolumn{2}{|c|}{$\begin{array}{c}\text { 95\% Confidence Interval for } \\
\text { Mean }\end{array}$} \\
\hline & & & $\begin{array}{l}\text { Lower } \\
\text { Bound }\end{array}$ & Upper Bound \\
\hline $\begin{array}{c}\text { Variolink }{ }^{\circledR} \\
\text { II }\end{array}$ & 72 & $\begin{array}{c}1.82 \\
(0.983)\end{array}$ & 1.59 & 2.05 \\
\hline $\begin{array}{c}\text { NX3 } \\
\text { Nexus }{ }^{\circledR}\end{array}$ & 72 & $\begin{array}{c}2.74 \\
(1.510)\end{array}$ & 2.38 & 3.09 \\
\hline $\begin{array}{l}\text { RelyX'M } \\
\text { U200 }\end{array}$ & 72 & $\begin{array}{c}1.82 \\
(1.282)\end{array}$ & 1.52 & 2.12 \\
\hline
\end{tabular}

Based on Levene's test for One-way ANOVA, $p$ $<0.05$, thus, assumption was not met. Therefore, Post Hoc Dunnentt 3 was used. Table 4 shows the comparison of microleakage scores between cements. There was a significant difference in the scores. The results of Post-Hoc comparisons between cements indicated that the mean microleakage score for Nexus ${ }^{\circledR} \mathrm{NX} 3$ cement was significantly higher compared to other subgroups of Variolink ${ }^{\circledR}$ II and RelyX ${ }^{\text {TMU}}$ 200. There was no statistically significant difference between those subgroups cemented with Variolink $^{\circledR}$ II and RelyX ${ }^{\mathrm{TM}}$ U200.

Table 4 Comparisons of mean (SD) microleakage 
scores between cements

\begin{tabular}{llll}
\hline Cements & $\begin{array}{l}\text { Mean (SD) } \\
\text { microleakage } \\
\text { scores }\end{array}$ & F statistics (df) & p value* \\
\hline Variolink $^{\circledR}$ II & $1.82(0.983)$ & & \\
NX3 Nexus ${ }^{\circledR}$ & $2.74(1.510)$ & $12.369(2,213)$ & 0.000 \\
RelyX $^{\text {TMU200 }}$ & $1.82(1.282)$ & & \\
\hline
\end{tabular}

One -way ANOVA

Post hoc analysis Dunnett T3: Variolink ${ }^{\circledR}$ II versus NX3 Nexus ${ }^{\circledR} p$ value $=.000, \mathrm{NX} 3$ Nexus ${ }^{\circledR}$ versus RelyX ${ }^{\mathrm{TM}} \mathrm{U} 200 p$ value $=.000$, other pair comparisons $p$ value $>0.05$

There was no interaction between blocks and cements as shown in Figure 1

Figures 3 a, b, c, d, e, f show interfacial morphology

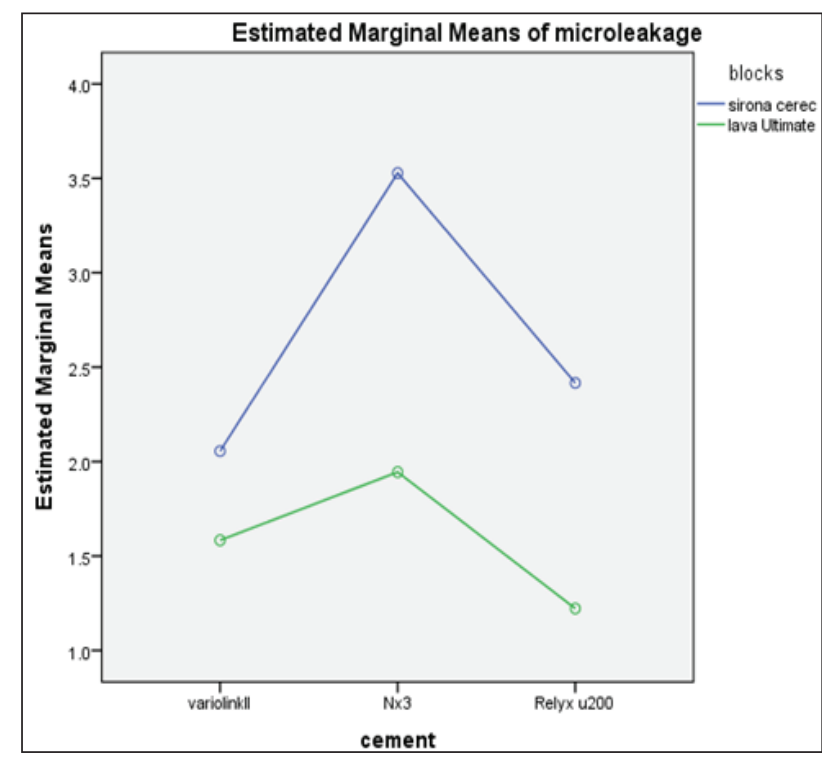

Figure 1 Interaction between blocks and cements

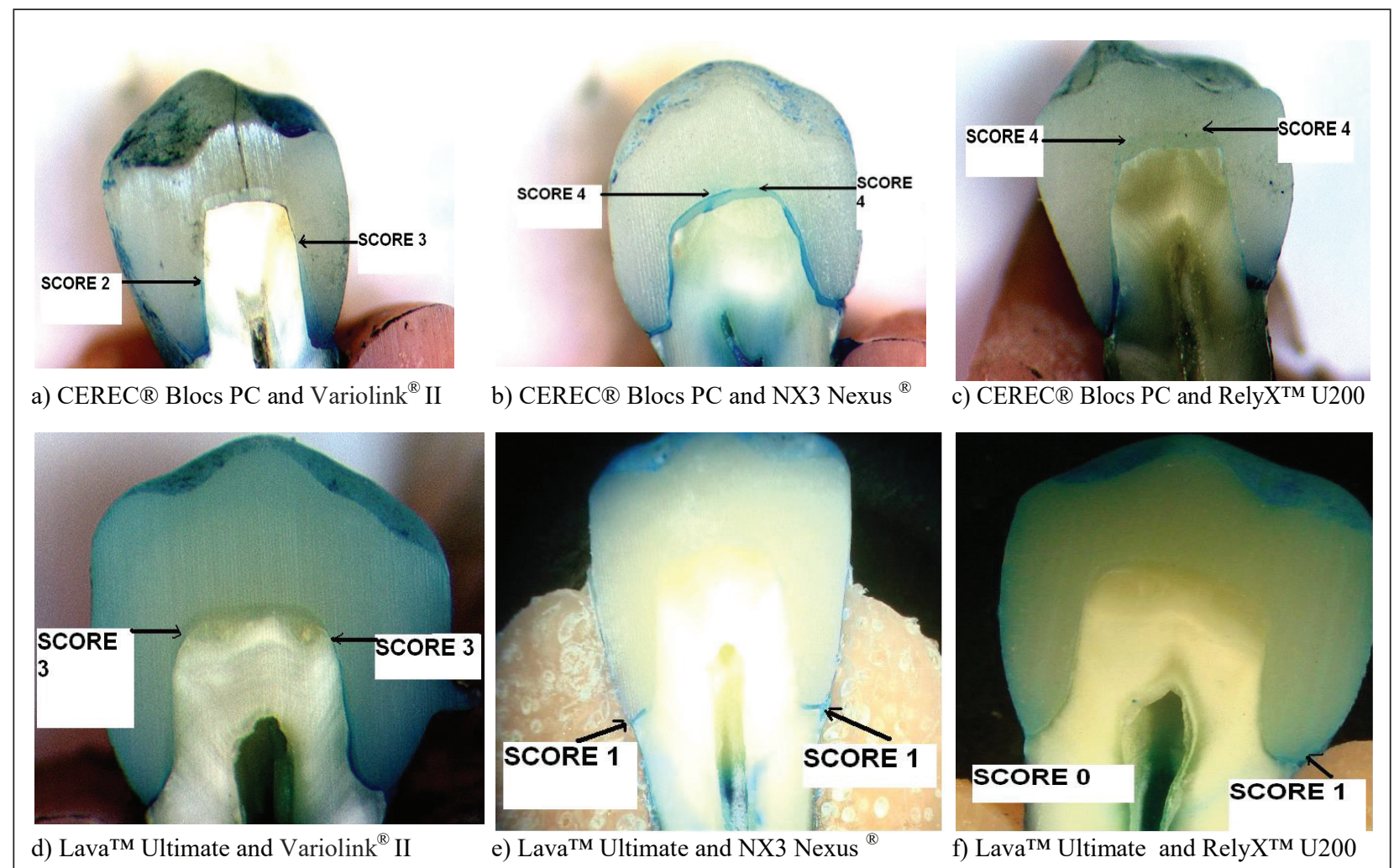

Figure $2 \mathrm{a}, \mathrm{b}, \mathrm{c}, \mathrm{d}, \mathrm{e}, \mathrm{f}$ illustrates the microleakage after dye staining between the six subgroups.

between cements to the dentine surface viewed under SEM (8000X magnification). All crowns cemented to the dentine with NX3 Nexus ${ }^{\circledR}$ (Figures $3 b$ and 3e) show greater gap formation compared to the other two cements regardless of the CAD/CAM blocks used. This finding is in accordance with the highest microleakage scores found in crowns cemented with
NX3 Nexus ${ }^{\circledR}$.

Cement to dentine interface in both Variolink ${ }^{\circledR}$ II and RelyX $X^{\mathrm{TM}} \mathrm{U} 200$ show similar gap formation shown in Figures 3a, 3c, 3d and 3f. This is also in accordance with their similar microleakage scores shown in Table 4 and Figure 2.

\section{Discussion:}




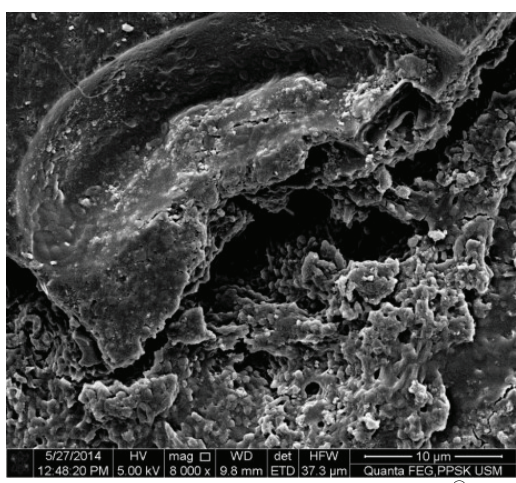

a) CEREC® Blocs PC and Variolink ${ }^{\circledR}$ II

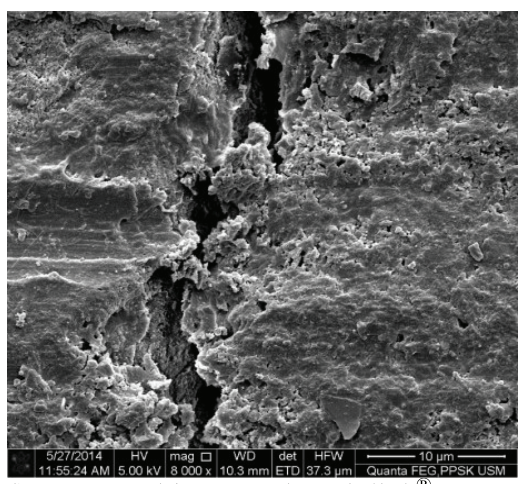

d) Lava ${ }^{\mathrm{TM}}$ Ultimate and Variolink ${ }^{B}$ II

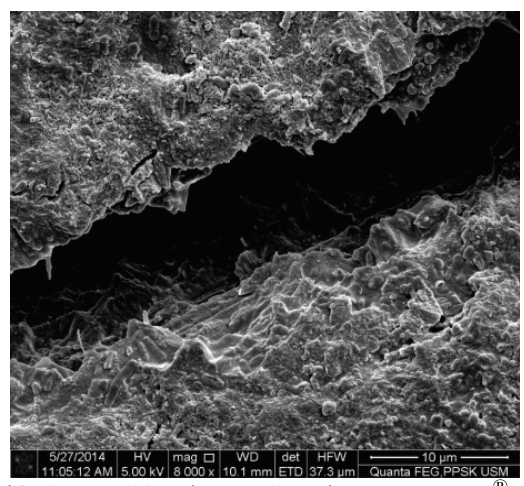

b) CEREC ${ }^{\circledR}$ Blocs PC and NX3 Nexus ${ }^{\circledR}$

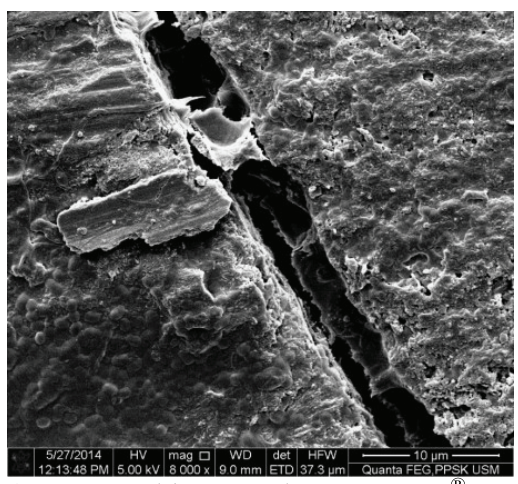

e) Lava ${ }^{\mathrm{TM}}$ Ultimate and NX3 Nexus

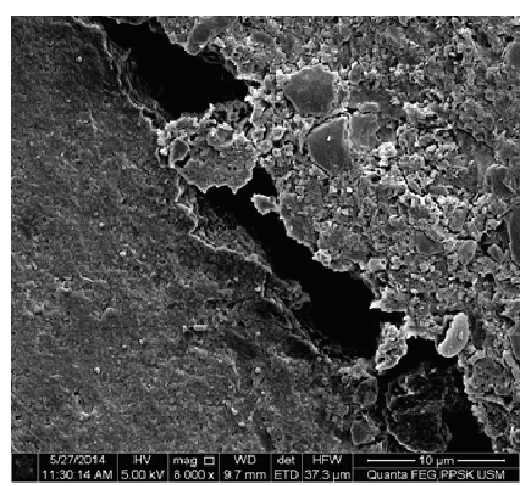

c) CEREC ${ }^{\circledR}$ Blocs PC and RelyX ${ }^{\mathrm{TM}} \mathrm{U} 200$

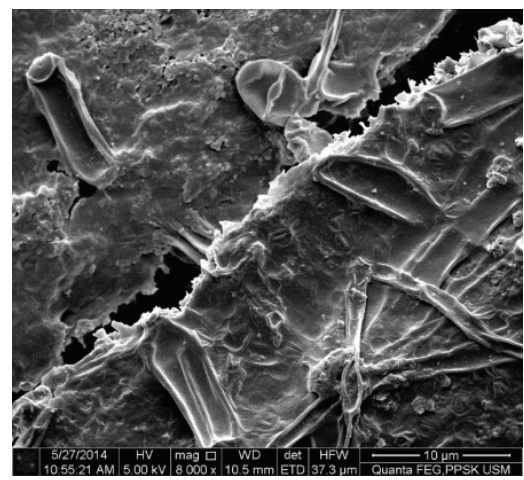

f) Lava ${ }^{\mathrm{TM}}$ Ultimate and RelyX ${ }^{\mathrm{TM}} \mathrm{U} 200$

Figures 3 a, b, c, d, e, f: SEM view of luting cement to dentin interface amongst the six subgroups

Lava $^{\mathrm{TM}}$ Ultimate resin nano ceramic block was the subject of this study as it is a new material with the uniqueness of both composite resin and zirconia. CEREC ${ }^{\circledR}$ Blocs PC was used in this study as a benchmark product. The oral environment produces cumulative effects such as temperature, $\mathrm{pH}$ fluctuation and mechanical loading. These effects are difficult to simulate in an in-vitro study. In this study however, the changing in temperature has been simulated with thermocycling procedure. However, the other challenges were not taken into consideration. Therefore, one needs to interpret the results of this study with caution. Clinically or in vivo, the performance of the crowns may be poorer than the results of this current study. Only one operator was used to conduct his study in order to minimise imprecision of the crown preparation and the cementation procedure. The operator has been single blinded to reduce potential bias. The $p$ value of independent $t$ test between different measurements of the data showed no significant difference between the two readings. This indicates that the assessment of the microleakage is reproducible and reliable.

The results obtained from this study revealed a significant difference between microleakage scores between the two blocks, with Lava ${ }^{\mathrm{TM}}$ Ultimate resin nano ceramic crowns showing significantly lower microleakage scores compared to conventional feldspathic ceramic blocks regardless of the types of cement used as luting agents. This is in agreement with another study. ${ }^{19}$ The possible explanation is that Lava ${ }^{\mathrm{TM}}$ Ultimate has a lower elastic modulus compared to conventional ceramic blocks, enabling Lava $^{\mathrm{TM}}$ Ultimate to reduce the restoration stress and fatigue which reduces microleakage. ${ }^{[20]}$ Furthermore, the flexural strength of Lava ${ }^{\mathrm{TM}}$ Ultimate is $200 \mathrm{MPa}$, and is considered high to the material. This is due to the nano particle clusters of zirconia embedded in a highly cross-linked polymer matrix. Our result is also in agreement with Akbar et al ${ }^{21}$ in 2006, who concluded that indirect composite is better to resist microleakage compared to conventional ceramics. However, in contrast, Ghazy et. al ${ }^{2}$ in 2010 found that the microleakage scores of both composite and porcelain crowns were similar. Results obtained by Kaseem et al ${ }^{15}$ in 2012 however also disagreed with the current study, in which they had higher mean of microleakage score for resin composites compared 
to ceramics. This might be due to the differences between the composite blocks structure used in their studies.

The microleakage scores were least pronounced in RelyX ${ }^{\text {TM }}$ U200 self-adhesive luting cement (single step), compared to NX3 Nexus ${ }^{\circledR}$ (two-step etchand-rinse adhesive) and Variolink ${ }^{\circledR}$ II/Syntac Clasic (three/multi step etch-and-rinse adhesive). This is in agreement with another study. ${ }^{22}$ Mormann et $a l^{23}$ in 2009 also agreed that self-adhesive one bottle in RelyX ${ }^{\mathrm{TM}} \mathrm{U} 200$ stands as a valid alternative to the conventional three bottle system total-etch representative (VariolinkII) and conventional GIC cement (Ketac Cem) with respect to marginal adaptation and fracture resistance in the cementation of CAD/CAM milled ceramic molars. Yuksel et al ${ }^{24}$ in 2011, also reported lower level of microleakage in CAD/CAM milled crowns cemented with selfadhesive luting agents compared to glass ionomers. In addition, Bindle ${ }^{25}$ in 2006 also stated that adhesive resin cements will increase the relatively weak strength of ceramic blocks and recommends using adhesive cements for lucite glass-ceramics or feldspathic crowns.

Contrary to the current results, Kaseem et al ${ }^{15}$ in 2012 reported that crowns cemented with Panavia F (self-etch resin cement) had significantly lower mean of microleakage score than those obtained with ones cemented with RelyX Unicem (self-adhesive cement). In addition, Ghazy et $a l^{2}$ in 2010, reported that there was lower microleakage score for $\mathrm{CAD} /$ CAM milled full crowns cemented with self-etch resin cement (Panavia II), compared to groups which used RelyX Unicem as a self-adhesive luting, irrespective of the crown materials used.

This might be explained by the differences in cements compositions. Both Kaseem ${ }^{15}$ (2012) and Ghazy $^{2}$ (2010) used Panavia F as the self-etch cement and RelyX Unicem as their self adhesive cement. The current study used RelyX ${ }^{\mathrm{TM}} \mathrm{U} 200$ as the self adhesive cement. MDP (10-Methacryloyloxydecyl di hydrogen phosphate) monomers are used in both PanaviaF2 and RelyX ${ }^{\mathrm{TM}}$ U200. MDP creates a strong chemical bond to hydroxyapatite in enamel, dentin and also with metal alloys. However, in addition, RelyX ${ }^{\mathrm{TM}} \mathrm{U} 200$ might also benefit from the additional chemical bonding between dentin and Vitrebond ${ }^{\mathrm{TM}}$ Copolymer that provides consistent bond under varying moisture levels ${ }^{20}$, hence the improved and positive results of RelyX ${ }^{\mathrm{TM}} \mathrm{U} 200$ self adhesive cement in the current study.

The three-step etch-and-rinse adhesives have been described as the bench mark to the newgeneration adhesives. ${ }^{26}$ However, in the current study, Variolink ${ }^{\circledR}$ II using multisteps etch-and-rinse adhesive bonding (Syntac Classic) gave a higher/ advanced microleakage scores compared to single step RelyX ${ }^{\mathrm{TM}}$ U200 self-adhesive luting cement. This lower performance of multistep etch-and-rinse adhesive bonding Variolink ${ }^{\circledR} \mathrm{II} /$ Syntac Classic is due to interaction of adhesive with the dentinal surface that may be very superficial. Other reasons were the adhesion deteriorating with time, and insufficiency in resisting debonding in the long term..$^{23}$

In the current study, regardless of types of blocks being used, NX3 Nexus ${ }^{\circledR}$ cement using two-step etch-and-rinse adhesive (Optibond Solo Plus) showed the highest microleakage scores compared to other cements. Peumans in $2005^{[26]}$ reported that the reducing in infiltration potential can lead to the two-step etch-and-rinse adhesives bond to become less effective as they have more complexity to fully infiltrate and demineralize the collagen mesh, and to remove all residual solvent compared to the three step etch-and-rinse version. In this study, the benefit from RelyX ${ }^{\mathrm{TM}} \mathrm{U} 200$ explained earlier, coupled with lower elastic modulus of Lava ${ }^{\mathrm{TM}}$ Ultimate resin nano ceramic crowns might explain the best result obtained by this combination.

The SEM images (Figure 3) obtained from representative samples under $8000 \mathrm{X}$ magnification also support microleakage results of this current study. Different types of resin cements resulted in different morphological images in dentin-adhesive level. NX3 Nexus $^{\circledR}$ cement resulted in greater gap formation compared with teeth cemented with RelyX ${ }^{\mathrm{TM}} \mathrm{U} 200$ or Variolink ${ }^{\circledR}$ II regardless of blocks. This is in agreement with other studies. ${ }^{27,28}$

From the results, it shows that there is no interaction between the blocks and cements that affects the microleakge scores. This is in agreement with another study by Ghazy et al $^{2} 2010$ who concluded that the cement properties and bonding system can affect microleakage scores irrespective of type of blocks which are used.

In-vivo environment is constantly changing; all the chemical, thermal and more importantly cyclic mechanical loading can lead to fatigue in restoration 
in long term. This in turn, will directly affect the microleakage pattern and seal ability of the materials. Further in-vivo research can be conducted to investigate these parameters and the effect on microleakage of the $\mathrm{CAD} / \mathrm{CAM}$ milling restorations.

\section{Conclusions}

By the limitation of this study, it can be concluded that crowns made with resin nano ceramic crowns, showed less microleakage than those made with feldspathic ceramic blocks. Crowns cemented with self-adhesive cement also showed less microleakage than those cemented with using two-step etch-andrinse adhesiv
Conflict of interest: "The authors declare(s) that there is no conflict of interest regarding the publication of this paper"

\section{Auther's contribution:}

Data gathering and idea owner of this study: Fard AY, Ab-Ghani Z, Ariffin Z, Mohamad D

Study design: Ab-Ghani $Z$

Data gathering: Fard AY, Ab-Ghani Z, Ariffin Z, Mohamad D

Writing and submitting manuscript: Ab-Ghani Z

Editing and approval of final draft: Fard AY, AbGhani Z, Ariffin Z, Mohamad D

\section{References:}

1. Fasbinder DJ, Dennison JB, Heys D, Neiva G. A clinical evaluation of chairside lithium disilicate CAD/CAM crowns: a two-year report. J Am Dent Assoc 2010; 141 Suppl 2, 10S-4S.

2. Ghazy M, El-mowafy O, Roperto R. Microleakage of porcelain and composite machined crowns cemented with self-adhesive or conventional resin cement. J Prosthodont 2010; 19(7):523-530. DOI: $10.1111 / j .1532-849 X .2010 .00637 . x$
3. Spitznagel FA., Horvath SD, Guess PC, Blatz MB. 'Resin Bond to Indirect Composite and New Ceramic/Polymer Materials: A Review of the Literature', J Esthet Restor Dent 2014;26(6):382-393. DOI: 10.1111 /jerd.12100

4. Kidd EA. Microleakage: a review. J Dent 1976; 4(5):199-206.

5. Bergenholtz G, Cox CF, Loesche WJ, Syed SA. Bacterial leakage around dental restorations: its effect on the dental pulp. J Oral Pathol 1982; 11(6):439-450. 
6. Goldman M, Laosonthorn P, White RR. Microleakage-full crowns and the dental pulp. J Endod 1992; 18:473-475. DOI:10.1016/S0099-2399(06)81345-2

7. El-mowafy $\mathrm{O}$. The use of resin cements in restorative dentistry to overcome retention problems. J Can Dent Assoc 2001; 67:97-102.

8. Bindl A, Mormann WH. Clinical and SEM evaluation of all-ceramic chair-side CAD/CAM-generated partial crowns. Eur J Oral Sci 2003; 111(2): 163-169. DOI: 10.1034/j.1600-0722.2003.00022.x

9. Technical Product Profile: RelyX Unicem. 3M ESPE AG, Seefeld Germany, 2002: 12.

10. Gernhardt CR, Bekes K, Schaller HG. Short-term retentive values of zirconium oxide posts cemented with glass ionomer and resin cement: an in vitro study and a case report. Quintessence Int 2005; 36:593-601.

Monticelli F, Osorio R, Mazzitelli C, Ferrari M, Toledano M. Limited decalcification/diffusion of self-adhesive cements into dentin. J Dent Res. 2008; 87(10):974-979.

11. Ferrari M, Mannocci F, Mason PN, Kugel G. In vitro leakage of resin-bonded all-porcelain crowns. J Adhes Dent 1999; 1:233-242.

12. De Munck J, Vargas M, Van Landuyt K, Hikita K, Lambrechts P, Van Meerbeek B. Bonding of an autoadhesive luting material to enamel and dentin. Dent Mater 2004; 20(10): 963-971.

DOI:10.1016/j.dental.2004.03.002

13. Behr M, Rosentritt M, Regnet $\mathrm{T}$, Lang R, Handel G. Marginal adaptation in dentin of a self-adhesive universal resin cement compared with welltried systems. Dent Mater 2004; 20: 191-197. http://dx.doi.org/10.1016/S0109-5641(03)00091-5

14. Kassem Amr S, Osama Atta and Omar El-Mowafy. Fatigue Resistance and Microleakage of CAD/ CAM Ceramic and Composite Molar Crowns. Journal of Prosthodontics 2012; 21 (1): 28-32. DOI: 10.1111/j.1532-849X.2011.00773.x

15. Lee JJ, Nettey-Marbell A, Cook A JR., Pimenta LA, Leonard $\mathrm{R}$, Ritter AV. Using extracted teeth for research: the effect of storage medium and sterilization on dentin bond strengths. J Am Dent Assoc 2007; 138(12): 1599-1603.

http://dx.doi.org/10.14219/jada.archive.2007.0110

16. Gale MS, Darvell BW. Thermal cycling procedures for laboratory testing of dental restorations. J Dent 1999; 27(2): 89-99.

http://dx.doi.org/10.1016/S0300-5712(98)00037-2

17. Yun Hao M, Ab Ghani Z, Masudi SM. Effect of different number of thermal cycling on marginal leakage of class $\mathrm{V}$ restoration using nano tooth coloured materials. Dentika Dental Journal 2010; 15(1): 10-14.

18. Tsitrou EA, Northeast SE, van Noort R. Evaluation of the marginal fit of three margin designs of resin composite crowns using CAD/CAM. J Dent 2007; 35 (1): 68-73. DOI:10.1016/j.jdent.2006.04.008

19. Technical Product Profile: Lava ${ }^{\mathrm{TM}}$ Ultimate CAD/CAM Restorative 3M ESPE St. Paul, MN, USA. 2011; 9-10.

20. Akbar JH, Petrie CS, Walker MP, Williams K, Eick JD. Marginal adaptation of Cerec 3 CAD/CAM composite crowns using two different finish line preparation designs. J Prosthodont 2006;15 (3): 155-163. DOI:10.1111/j.1532-849X.2006.00095.x

21. Martinez-Rus F, et al. Influence of CAD/CAM systems and cement selection on marginal discrepancy of zirconia-based ceramic crowns. Am J Dent 2012; 25 (2): 67-72.

22. Mormann W, et al. Effect of two self-adhesive cements on marginal adaptation and strength of esthetic ceramic CAD/ CAM molar crowns. J Prosthodont 2009; 18 (5): 403-410. doi: 10.1111/j.1532-849X.2009.00461.x

23. Yüksel E1, Zaimoğlu A. Influence of marginal fit and cement types on microleakage of all-ceramic crown systems. Braz Oral Res 2011;25 (3): 261-266. http://dx.doi.org/10.1590/S1806-83242011000300012

24. Bindl A, Luthy H, Mormann WH. Strength and fracture pattern of monolithic CAD/CAM-generated posterior crowns. Dent Mater 2006; 22 (1): 29-36. DOI:10.1016/j.dental.2005.02.007

25. Peumans M, Kanumilli P, De Munck J, Van Landuyt K, Lambrechts P, Van Meerbeek B. Clinical effectiveness of contemporary adhesives: A systematic review of current clinical trials. Dent Mater 2005; 21(9): 864-881. DOI:10.1016/j.dental.2005.02.003

26. Van Meerbeek B, Conn LJ Jr, Duke ES, Eick JD, Robinson SJ. Guerrero D. Correlative transmission electron microscopy examination of nondemineralized anddemineralized resin-dentin interfaces formed by two dentin adhesive systems. J Dent Res 1996; 75 (3):879-888. doi: 10.1177/00220345960750030401

27. Macari S, Gonçalves M, Nonaka T. Scanning Electron Microscopy Evaluation of the Interface of Three Adhesive Systems. Braz Dent J 2002; 13(1): 33-38. 